\title{
«Con licencia de la devoción y privilegio del regozijo»: las siestas en las celebraciones religiosas extraordinarias de la Valencia seiscentista
}

\author{
With license of devotion and privilege of rejoicing: Siestas in extraordinary \\ religious celebrations of seventeenth century Valencia
}

\author{
Francesc Villanueva Serrano \\ Investigador Free-lance \\ fvilanue@hotmail.com
}

ORCID iD: http://orcid.org/0000-0002-4680-1546

\begin{abstract}
RESUMEN
Las siestas o sesiones musicales vespertinas en los templos hispánicos son un objeto de estudio relativamente reciente. Su celebración suele asociarse a las festividades eucarísticas, en las cuales cumplía la función de atraer público a la adoración del Santísimo Sacramento, patente en el altar, y a los posteriores oficios de vísperas y completas. Las relaciones de fiestas valencianas del siglo XVII muestran diáfanamente que estos actos -al igual que otros poéticos, dancísticos o combinación de ellos- tuvieron lugar asimismo en diversos templos de la ciudad durante las jornadas festivas de las grandes celebraciones extraordinarias ante otros objetos de veneración relacionados con el asunto particular como reliquias o imágenes. La minuciosidad de algunas descripciones también ayuda a conocer mejor cómo transcurrían estos eventos.
\end{abstract}

Palabras clave: Siestas, Valencia, siglo XVII, relaciones de fiestas, villancicos.

\begin{abstract}
Siestas or vespertine music sessions in Hispanic temples are a relatively recent object of study. This kind of events is usually associated to the eucharistic holidays, in which they fulfilled the function of attracting public to the adoration of the Blessed Sacrament, patent on the altar, and to the subsequent Offices of Vespers and Compline. The Valencian relaciones de fiestas (reports of feasts) of the seventeenth century clearly demonstrate that this events - like other poetic, dance or combination of them- also took place in various temples of the city during the festive days of the great extraordinary feasts before other objects of veneration related to the particular matter, as relics or images. The thoroughness of some descriptions also helps to better understand how these events were.
\end{abstract}

Key words: Siestas, Valencia, XVIIth century, relaciones de fiestas, villancicos. 


\section{FRANCESC VillanUEVA SERRANO}

Villanueva Serrano, F. (2018). «Con licencia de la devoción y privilegio del regozijo»: las siestas en las celebraciones religiosas extraordinarias de la Valencia seiscentista. Cuadernos de Investigación Musical, 2018, $\mathrm{n}^{\circ}$ extraordinario, 89-114.

doi: $10.18239 /$ invesmusic.v0i0.1942

\section{INTRODUCCIÓN}

Hasta hace apenas dos décadas, nuestros conocimientos acerca de los contextos para la música en los templos hispánicos durante la Edad Moderna estaban focalizados en los actos ceremoniales: las celebraciones litúrgicas y -aunque en mucha menor medida - las paralitúrgicas. En cualquier caso, se asumía que, en las iglesias, la música era un elemento que tenía su razón de ser en las ceremonias religiosas por lo que, en consecuencia, estaba indefectiblemente vinculado a estas. A pesar de ello, es cierto que unos pocos documentos aislados exhumados en algunos centros catedralicios peninsulares procedentes de los siglos XVII a XIX apuntaban ya entonces la existencia de cierta actividad musical desligada de la acción ceremonial. En 1983, apoyándose en algunos de estos testimonios, José López-Calo definía brevemente el concepto de siesta como unos "conciertos sacros, en los que tomaban parte los cantores y ministriles, bien juntos o bien alternándose, durante la octava del Corpus, en que se tenía el Santísimo Sacramento expuesto durante todo el día" (LópezCalo, 1983: 120-121). Quince años más tarde, Pablo L. Rodríguez estudiaba la presencia de villancicos y tonos al Santísimo Sacramento en las siestas seiscentistas que, con motivo de la celebración mensual de las Cuarenta Horas, tuvieron lugar en la capilla del Alcázar Real de Madrid desde 1644 (Rodríguez, 1997/1998) ${ }^{1}$. Pero hay que esperar hasta el año 2002 para la aparición de los primeros estudios monográficos de calado sobre estos actos musicales desvinculados del ceremonial religioso. A partir de una labor de recopilación y análisis de la documentación hasta entonces disponible, dispersa en diversas publicaciones, Antonio Ezquerro y Dámaso García Fraile consiguieron separadamente en sendos trabajos delinear una primera caracterización con semejantes resultados sobre la naturaleza de las siestas y su evolución en el tiempo (Ezquerro Esteban, 2002; García Fraile, 2002)². A grandes rasgos, se admitía, aunque se ampliaba algo, la idea apuntada por López-Calo al considerar que estas sesiones musicales a modo de conciertos espirituales tuvieron lugar en horario vespertino ante el Santísimo Sacramento patente en exposición pública -fundamentalmente, pero no exclusivamente, en la octava de la festividad del Corpus Christi- durante los espacios de tiempo que quedaban entre los oficios, con la finalidad primordial de atraer a los ciudadanos a la iglesia. Asimismo, se sugirió el origen cronológico de las siestas a finales del siglo XVI, como también había apuntado López-Calo, a partir del primer documento de época recopilado que ya testimoniaba inequívocamente esta práctica en la catedral de Palencia en 1602, cuando parece que allí se implantó. Para apoyar esta aproximación, García Fraile identificó a lo largo del Quinientos algunos actos que

\footnotetext{
${ }^{1}$ Parte de la información sobre siestas puede encontrarse también en Rodríguez, 2007: 194-198.

2 Posteriormente, este último autor ha publicado un trabajo de contenido similar. Véase García Fraile, 2008.
} 

RELIGIOSAS EXTRAORDINARIAS DE LA VALENCIA SEISCENTISTA

consideró precedentes de las siestas, tales como la música que se interpretaba en el momento del encierro del Santísimo o breves acciones dramáticas —algunas con danzasen la octava del Corpus Christi (Ezquerro Esteban, 2002: 1004; García Fraile, 2002: 379381). La información disponible para ambos autores en el momento de la redacción de sus respectivos trabajos apuntaba a que, entrado el siglo XVIII, se interrumpía la constante asociación de las siestas a las festividades del Santísimo Sacramento, atendiendo a que de esta centuria ya se conocía algún testimonio, aunque aislado, de estas prácticas en celebraciones diferentes (Ezquerro Esteban, 2002: 1006; García Fraile, 2002: 401). Las siestas perduraron hasta el siglo XIX.

Los influyentes estudios de Ezquerro y García han sido el punto de arranque y, quizá también, un estímulo para la aparición de nueva información sobre estos actos musicales en las publicaciones más recientes. De hecho, tras ellos han aflorado con mayor frecuencia documentos inéditos sobre las siestas en diversos templos del territorio hispánico ${ }^{3}$, e incluso se ha tratado nuevamente la cuestión general en algunos trabajos (López-Calo, 2012: 457-459; Torrente, 2016: 475-483). La ciudad de Valencia ha sido, precisamente, uno de los centros urbanos de donde mayor volumen de nueva información ha visto la luz gracias, fundamentalmente, a los estudios de Ramón Ramírez y Andrea Bombi, que se refieren al período comprendido entre mediados del siglo XVII y las primeras décadas del siglo XIX. El primero dirigió especialmente su foco de atención hacia la catedral mientras que el segundo se fijó detenidamente en la actividad promovida por los frailes dominicos en su convento de Santo Domingo y los jesuitas en su Casa Profesa ${ }^{4}$. En el presente artículo se profundizará en el estudio de estas sesiones musicales en la capital valenciana durante el siglo XVII, especialmente en su más desconocida primera mitad, a través de la información que proporcionan las relaciones de fiestas publicadas en este período. Este género de literatura memorialística se caracteriza por sus minuciosas descripciones del desarrollo de grandes celebraciones públicas —normalmente en el ámbito de una ciudad o de un templo- tales como beatificaciones, canonizaciones, llegada de reliquias, exequias de personas relevantes o inauguraciones de capillas 5 . Usualmente eran obras impresas poco después del acontecimiento por personas de algún modo implicadas en los actos, por lo

\footnotetext{
3 Robledo Estaire, 2006: 498, 502-503, 506, 509, 514, 515-520 [siglo XVII, Madrid, cofradías, festividades varias]; Hathaway, 2007: 220, 223-225 [1656, Madrid, iglesia de San Ginés, fiestas por la traslación de la imagen del Santo Cristo]; Bejarano Pellicer, 2013: 430, 433, 437 [siglo XVII, Sevilla, conventos, festividades del Santísimo Sacramento]; Robledo Estaire, 2013: 111, 113, 114-120, 122-123, 125-126 [siglo XVII, Madrid, cofradía del Ave María, festividades varias]; Knighton y Mazuela-Anguita, 2015: 238, 242-243 [1614, Cataluña, catedrales y conventos, fiestas por la canonización de Santa Teresa de Jesús]; Garbayo Montabes, 2015: 276, 286-287 [aprox. 1750-1900, Santiago de Compostela, catedral, octava del Corpus Christi].

4 Olson, 2005: 284-285 [1600, catedral, llegada de reliquia de San Vicente Ferrer]; Ramírez i Beneyto, 2006: [aprox. 1650-1820, catedral y parroquias, fiestas sacramentales y otras]; Bombi, 2007: 180 [1680, convento de Santa Úrsula]; Ferrer Ballester, 2007: 155 [1700c, catedral, octava de Corpus Christi]; Bombi, 2012, vol 1: 105, 108, 221; ibid., vol. 2: 12-14, 96-97, 114, 116-119; 130-135, 238, 245, 248, 256, 340, 353, 359, 368, 374, 381, 397, 405 [aprox. 1675-1800, catedral y conventos, festividades varias]; Bombi, 2015: 161-162, 165, 175, 179, 192-194 [siglos XVII y XVIII, casa profesa de la Compañía de Jesús, festividades varias]; Bombi, 2017 [siglo XVII, Valencia, convento de Santo Domingo].

${ }^{5}$ Un catálogo de este tipo de literatura en el ámbito hispánico puede encontrarse en Alenda y Mira, 1903. Para el caso valenciano del presente estudio, véase Carreres Zacarés, 1925.
} 


\section{FranCESC VillanUeVa SERRANo}

que suelen mantener un acusado tono panegírico que no debe olvidarse, especialmente a la hora de valorar expresiones de índole subjetiva. Pese a ello, el carácter intrínsecamente extraordinario de los eventos a que se dedican estos libros los reviste de un gran valor como instrumentos para indagar en unos acontecimientos que suelen dejar mínimos rastros en los más conocidos archivos catedralicios, puesto que frecuentemente se sufragaban de forma compartida por diversos patrocinadores tales como las ciudades, los centros conventuales o incluso personajes poderosos. En particular, las relaciones de fiestas resultan de especial provecho para el estudio de las siestas en el contexto todavía muy oscuro de las celebraciones hispánicas no eucarísticas ${ }^{6}$. Los resultados obtenidos en el ámbito valenciano se confrontarán con el conocimiento actual sobre estos actos en la península con el fin de tratar de determinar el grado de integración de estas prácticas locales en el contexto hispano.

\section{FIESTAS POR LA TRASLACIÓN DE UNA RELIQUIA DE SAN VICENTE FERRER (1600)}

El canónigo valenciano Francisco Tárrega escribió y publicó en 1600 una relación describiendo las festejos que tuvieron lugar del 16 al 23 de julio del mismo año por la traslación a la catedral de una reliquia - concretamente, una costilla- de san Vicente Ferrer. Esta obra puede considerarse como la primera relación conservada de una celebración religiosa en el ámbito valenciano. En estas mismas fiestas ya se constata con absoluta claridad la celebración de sesiones musicales en la catedral independientes del ceremonial:

16-jul-1600, procesión general y llegada de la reliquia a la catedral.

[1] 17-jul-1600, catedral, exposición de la reliquia en el altar mayor. "[p. 21] A la una vino el perlado al altar mayor, donde concurriendo gran parte de la nobleza, religión y gobierno d'esta ciudad y mucho número de otras gentes, començó la música que para todo el ochavario estava señalada. Havía un juego de vihuelas de arco con que se tañían varios motetes, ensaladas y villancicos con grande suavidad y destreza; estava otro de menestriles, cornetas y flautas que le correspondía; un organillo lleno de artificios y mixturas, y todos los cantores de la yglesia, que son muy diestros y de bozes muy alabadas. De toda esta música se hazían mil maneras de conciertos y choros, quando juntando las bozes con las vihuelas, quando concertando el órgano con ellas y con los menestriles y quando mezclándose todos con una confusión no menos apazible que ordenada. Esta diversidad de armonías, que arrebatava los [p. 22] sentidos entre'l silencio de infinita gente y la devoción d'ella y del lugar, durava cada día desde la una hasta las tres de la tarde y entonces, aviendo cantado a choros el psalmo Cum invocarem, mucha parte de los buenos ingenios naturales y estrangeros que hazen famosa esta ciudad leýan versos en alabança del glorioso santo. (...) [p. 59] Acabáronse de leer los versos sobredichos y con ellos se acabó la música de este día y se dixeron las vísperas y completas $(\ldots)$ ".

\footnotetext{
${ }^{6}$ Esta utilidad ya se ha puesto de manifiesto para el caso de las fiestas madrileñas por la traslación de la imagen del Santo Cristo de San Ginés en 1656 a su nueva capilla (Robledo Estaire, 2006: 502-506, 515-520; Hathaway, 2007).
} 

RELIGIOSAS EXTRAORDINARIAS DE LA VALENCIA SEISCENTISTA

[2] 18-jul-1600, catedral, exposición de la reliquia en el altar de Todos los Santos. "[p. 60] Y acabado el officio [misa] vino el perlado a la capilla, donde huvo la música que arriba se ha referido; y con un organillo, y un violín y guitarras cantaron este día y todos los siguientes sobre libros algunos ecclesiásticos, cavalleros y hombres honrrados maravillosamente; y acabada la música se leyeron los versos que se siguen (...)”.

[3] 19-jul-1600, catedral, exposición de la reliquia en el altar mayor. "[p. 82] Miércoles, a dezinueve del sobredicho mes de julio, con la acostumbrada solemnidad y regozijo, se puso la reliquia en el altar mayor y se dixo la missa, y huvo sermón. Y a la hora de la música leyeron las coblas que se siguen (...)".

[4] 20-jul-1600, catedral, exposición de la reliquia en el altar mayor. "[p. 118] Vinieron el jueves a los veynte del sobredicho mes y año los condes de Benavente y toda su casa a la música ordinaria, que no lo fue ese día con tan calificada y devota assistencia. Los ingenios y regozijos se esmeraron; y huvo una dança de diversas naciones muy bien concertada $\mathrm{y}$ vestida. I acabada ella, se oyeron con mucha atención y gusto estas obras (...) [poesías]".

[5] 16 a 23-jul-1600, catedral, exposición de la reliquia en el altar mayor. "[p. 319] La capilla de cantores y las guitarras, violín y órgano, cantaron en el discurso d'estos ocho días estas letrillas vertidas de otras humanas, que para acudir a la puntual devoción d'esta tierra, ha parecido que fuessen remate del presente libro. (...) [1 romance; 2 folias; 4 villancicos; 1 soneto]" (Tárrega, 16007).

Como se comprueba ya en este caso, y se verificará en los sucesivos, en este género de celebraciones de carácter extraordinario, de modo semejante a otras grandes festividades ordinarias como el Corpus Christi, los festejos no se solían limitar al día principal, sino que se programaban actos durante otras jornadas normalmente consecutivas, con frecuencia a lo largo de toda una octava, como sucedió en esta ocasión. El primer día, la festividad propiamente dicha, solía haber misa solemne por la mañana y procesión general por la tarde. En el resto de días festivos, solía celebrarse por la mañana una misa solemne con sermón y, por la tarde, el programa litúrgico de los oficios de vísperas y completas se solía complementar con sesiones extralitúrgicas que podían constar de música, poesía - simplemente una lectura o bien un certamen- y, con mucha menor frecuencia, danza. Estos tres elementos podían encontrarse separados o en algún tipo de combinación. En este caso, música y poesía se hallan separadas y solo en uno de los días hubo danza, que parece que se interpoló entre la música y la poesía. La interesante descripción del acto del día 16 de julio, merece algunas observaciones. Por una parte, se trata del primer ejemplo hasta ahora conocido de una amplia sesión musical — de dos horas- desligada del ceremonial la cual, además, no tuvo lugar en una festividad relacionada con el Santísimo Sacramento, ni siquiera ante este, puesto que en este caso fue la reliquia del santo la que estuvo patente. En segundo lugar, el autor no emplea el término siesta para referirse a este acto sino simplemente música, concepto en que además incluye la lectura de poesía que,

\footnotetext{
${ }^{7}$ Páginación indicada en el texto. Todos los textos transcritos en este trabajo se han modernizado en cuanto a acentuación gráfica, signos de puntuación y uso de u/v y i/j. Asimismo, se han separado las palabras que aparecen juntas, bien con espacios o con apóstrofes.
} 


\section{FranCESC VillanUeVa SERRANo}

tanto en este día como en el posterior, siguió a las interpretaciones musicales, así como la danza del 20 de julio. Por último, aunque Tárrega no detalla el programa de piezas de la sesión musical, queda suficientemente patente su naturaleza muy variada en cuanto a los intérpretes - entre los cuales participó incluso el conjunto no residente en la catedral de vihuelas de arco-y sus combinaciones así como en lo que se refiere al repertorio, entre el que se incluye tanto música en romance - ensaladas y villancicos-como en latín - motetes y un salmo-. En días posteriores actuaron, además, un violín ${ }^{8}$ y unas guitarras que acompañaban el canto de letrillas vertidas a lo divino a cargo de personas que no eran músicos profesionales sino clérigos, caballeros y ciudadanos' ${ }^{9}$ La pieza que puso fin a la parte musical del día 26 fue el salmo 4 Cum invocarem que parece que se interpretó en una versión policoral, el formato más espectacular que también tenían los villancicos que solían finalizar las siestas en la iglesia de San Ginés de Madrid en las fiestas de 1656 por la traslación del Santo Cristo a su nueva capilla (Robledo Estaire, 2006: 515-520) o las celebradas en el convento de San Francisco madrileño el 11 y 12 de octubre de 1692 (Rodríguez, 1997/1998: 37).

\section{Fiestas Por la CANONización de RAimundo de PeÑafort (1602)}

Solo año y medio más tarde se celebró también especialmente la canonización de Raimundo de Peñafort, fraile dominico catalán, que había sido decretada en Roma el 29 de abril de 1601 por el papa Clemente VIII. Al pertenecer el nuevo santo a la orden de Predicadores, el templo que acogió las celebraciones fue la iglesia del convento de Santo Domingo, principal centro de los dominicos en el reino valenciano. Nuevamente, encontramos descritas sesiones vespertinas de música con el nombre de música durante los días siguientes a la jornada festiva principal celebrada el 7 de enero de 1602, que en este caso nos transmite el cronista Vicente Gómez, doctor en Teología y fraile del convento:

\section{7-ene-1602, festividad de San Ramón de Peñafort y procesión general.}

[6] 8-ene-1602, convento de Santo Domingo. "[p. 105] Acabado el sermón y la missa fueron los religiosos a comer; y esso fue muy aprissa, porque apenas se acabó la fiesta de por la mañana, que ya la yglesia estava llena de gente para ver la de la tarde. Luego, después de comer, se dixeron vísperas con la solenidad y gravedad que esta casa acostumbra, començó la música. En la capilla mayor avía un juego de vihuelas de arco con todas las voces dobladas que, tocadas por diestros músicos y acompañadas con regaladíssimas bozes de la capilla de la Yglesia Mayor, suspendían a los oyentes; y para variedad hazían differentes misturas los dos organitos que tiene esta casa y los menestriles con chirimías, flautas y cornetas; unas vezes cantavan con el órgano a una boz, otras todos juntos retratavan, remedándose y respondiéndose la celestial melodía que S. Juan oyó que le cantavan al Cordero Dios en el

\footnotetext{
${ }^{8}$ Es infrecuente esta denominación en esta época, atendiendo a que entonces todos los instrumentos de la familia del actual violín era denominados genéricamente violones (Robledo Estaire, 1986). Es probable que, por ser el más pequeño, el instrumento tiple de la familia entonces ya recibiera la denominación actual de violín. ${ }_{9}^{9}$ Sobre la práctica musical y literaria entre la nobleza valenciana de finales de siglo, véase Bombi, 2008.
} 

RELIGIOSAS EXTRAORDINARIAS DE LA VALENCIA SEISCENTISTA

cielo; y para remate cantavan el psalmo Cum invocarem a cuatro capillas y otras vezes el regaladíssimo Laudate Dominum in Sanctis ejus, que oyéndole quantos en la yglesia estavan, les parecía començar con tal regalo a gozar de aquella bienaventurança".

[7] 9-ene-1602, convento de Santo Domingo. "[p. 159] Con la acostumbrada solenidad se acabó la missa. Y luego, después de medio día, estando ya la iglesia tan llena de gente que no cabían de pies, dichas vísperas y completas se dio principio a la regalada y no menos grave música de las vihuelas de arco; y, partidos en dos choros los cantores de la seo, unos en una capilla donde estava un organito de muy curiosas misturas, y otros en otra al otro lado del altar mayor con otro órgano muy lindo, cantaron a versos el psalmo Laudate Dominum in Sanctis eius, saliendo todos juntos al verso Omnis Spiritus laudes Dominum con tal destreza y con tan [p. 160] extraordinaria melodía junta con mucha devoción, que verdaderamente parescía que todos los soberanos espíritus andavan en aquella capilla; otras letrillas se cantavan interpoladas muy curiosas; y a ratos con el un organito tañía un rabel destríssimamente que parescía muy bien. A las cuatro de la tarde se puso pausa en la música para dar lugar a las musas [poetas] que represadas del día antes venían con fervorosos desseos de hazer alarde en honra del santo de sus regalados pensamientos".

[8] 10-ene-1602, convento de Santo Domingo. "[p. 247] Luego acabada la missa con la acostumbrada solenidad, se fue la gente a sus casas, y no tardaron en volver, que a la una en punto ya no havia por dónde entrar en la Iglesia. Dixéronse vísperas y completas, y luego començó la música de vihuelas de arco; y esta tarde estuvo en la capilla mayor el señor Patriarca, suspendiendo aquel su grande espíritu con la extraordinaria suavidad de la música, y honrando con su presencia y gravedad nuestras fiestas".

[9] 11-ene-1602, convento de Santo Domingo. "[p. 308] Dichas vísperas y completas se començó como los otros días el exercicio regalado de los orfeos, que con diversidad de músicos instrumentos, vigüelas, [p. 309] rabeles, órganos, chirimías, cornetas y bozes escogidíssimas hazían bivo retrato de la celestial melodía; paró esta música a las tres y media de la tarde, y començaron los poetas".

[10] 12-ene-1602, convento de Santo Domingo. "[p. 368] Luego a la una hora después de haver comido, y dichas vísperas y completas, se començó la diversidad de música y prosiguió hasta que començaron los siguientes poetas" (Gómez, 1602¹0).

De modo similar a como sucedió en las fiestas anteriores, en estos días hubo largas sesiones de música seguidas de otras de poesía aunque, en este caso, todas ellas tuvieron lugar tras los oficios vespertinos, contrastando así con el orden inverso dominante en las siestas eucarísticas. Las descripciones de Gómez transmiten similar riqueza en los géneros de música vocal interpretados y en los medios musicales involucrados sobre los cuales, incluso, se aportan mayores detalles. En este sentido, se precisa que las vihuelas de arco presentes el 8 de enero tenían "todas las voces dobladas", lo que sugiere un numeroso conjunto de ocho miembros. Además, se usaron los dos organitos del convento que, al menos al día siguiente, estaban separados en diversas capillas de la iglesia, en cada una de las cuales también se ubicaron sendos grupos de cantores catedralicios para interpretar el

10 Paginación indicada en el texto. 


\section{FranCESC VillanUeVa SERRANo}

salmo Laudate Dominum, parece que alternándose el canto de los versos con el acompañamiento de estos instrumentos. El cronista atestigua inequívocamente la ejecución de música instrumental a modo de interludios entre las piezas vocales a cargo de un rabel ${ }^{11}$ que tañía junto a uno de los organitos.

\section{FieSTAS POR LA BEATIFICACIÓN DE SAN LUIS BERTRÁN (1608)}

La orden de Predicadores volvió a estar de enhorabuena unos años más tarde, ya que otro antiguo fraile valenciano, fray Luis Bertrán fue beatificado el 19 de julio de 1608 por Pablo V. Fray Vicente Gómez también se encargó de narrar las fiestas de la octava que organizó su convento para celebrar tal acontecimiento del 31 de agosto al 7 de septiembre del mismo año. En este caso, las actividades vespertinas fueron más variadas:

\section{1-ago-1608, domingo, procesión general.}

[11] 1-sept-1608, lunes, convento de Santo Domingo, exposición de la reliquia del santo. "[p. 107] Este día después de comer, antes que se començasse a representar una comedia de la vida y milagros del santo, se leyeron en la yglesia de Predicadores los versos siguientes: (...)".

[12] 2-sept-1608, martes, convento de Santo Domingo, exposición de la reliquia del santo.. "[p. 145] Luego, después de mediodía, se llenó la yglesia de Predicadores de gente, que aficionados al santo exercicio de la mañana en que tan doctamente y con tanto spíritu se predicaron las grandezas del santo, desseavan también oyrlas cantar a los excelentes poetas, que fueron muchos y muy buenos. Este día, assí ellos como los músicos y cantores de la Yglesia Mayor se aventajaron a sí proprios, obligados del sugeto, de la fiesta y de la assistencia del Excel señor Patriarcha, que quiso honrarla. Uvo una divina competencia entre las sabias musas y los regaladíssimos orfeos, que resultó en mucha honra del santo, y dio extraordinario gusto a los oyentes $(\ldots)$ ".

[13] 3-sept-1608, miércoles, convento de Santo Domingo, exposición de la reliquia del santo. "[p. 232] Entretanto que se apercibieron las cañas y se jugaron se prosiguió en la yglesia de Predicadores la justa de los ingeniosos poetas y se leyeron los versos que aquí se ponen: (...)".

[14] 4-sept-1608, jueves, convento de Santo Domingo, exposición de la reliquia del santo. "[p. 281] Este día en la tarde se corrieron también toros (...) Prosiguiose en la yglesia de Predicadores el exercicio de la poesía y leyéronse estos versos: (...)".

[15] 5-sept-1608, viernes, convento de Santo Domingo, exposición de la reliquia del santo. "[p. 368] Prosiguiose, acabadas vísperas, la música y divinos solazes que dieron los cantores de la yglesia mayor y los músicos, cantando letrillas regaladíssimas y tocando varios instrumentos, leyendo de quando en quando los versos siguientes: (...)".

[16] 6-sept-1608, sábado, convento de Santo Domingo, exposición de la reliquia del santo. "[p. 452] Prosiguiose, acabadas vísperas, la música y poesía con la suavidad y regalo de los otros días; y leyéronse (entre otro muchos) estos versos (...). Con esta poesía y otras muchas, que

\footnotetext{
${ }^{11}$ Es posible que este instrumento fuese el mismo que el cronista Tárrega denominaba violín.
} 


\section{«CON LICENCIA DE LA DEVOCIÓN Y PRIVILEGIO DEL REGOZIJO»: LAS SIESTAS EN LAS CELEBRACIONES RELIGIOSAS EXTRAORDINARIAS DE LA VALENCIA SEISCENTISTA}

aunque por buenas merecían este lugar y grande alabança, las dexo por que no crezca sobradamente este libro; y con regaladíssima música se dio fin al exercicio d'este día (...)”.

[17] 7-sept-1608, domingo, convento de Santo Domingo, exposición de la reliquia del santo. "[p. 493] Luego después de comer, uvo en la yglesia tres grandes tablados: uno para los jurados (...); en otro tablado estavan los juezes que lo avían de ser de la justa poética (...)" (Gómez, $\left.16099^{12}\right)$.

Así pues, la poesía parece que fue en este caso la protagonista de las veladas vespertinas en la iglesia de Predicadores durante toda la octava, que incluso se culminó con un certamen poético. No obstante, también hubo espacio para la música, que es reseñada por el cronista en tres de los días de la octava, aunque sin brindarnos en esta ocasión apenas detalles más allá de la presencia de los cantores de la catedral y de instrumentistas interpretando letrillas. En todo caso, la narración parece apuntar a que las interpretaciones musicales estaban intercaladas entre la lectura de las poesías, a diferencia con lo que había sucedido en las sesiones de las celebraciones anteriores.

\section{Fiestas POR LA Llegada de NUEVAS ReliQuias de SAN Vicente FerRer (1611)}

La llegada de nuevas reliquias de San Vicente Ferrer el 4 de agosto de 1611 al convento de Santo Domingo, donadas por la reina de Francia María de Médici, puso el broche a una década dorada de celebraciones en esta institución. En esta ocasión se encargó de dejar memoria escrita de la octava festiva otro hijo del convento: el aragonés Pedro Blasco. Por las tardes, el templo acogió todos los días actividad extraceremonial:

\section{4-ago-1611, jueves, festividad de Santo Domingo, llegada de la reliquia.}

[18] “[p. 40] (...) y a mí me mandaron que [p. 41] fuesse medio para que en la iglesia de Predicadores se tuviesse la santa reliquia patente ocho días y se celebrasse ochavario muy solene con missa, sermón, música y [...] luminaria, y todas las tardes se empleassen con menestriles, cantores, poetas y otros exercicios regozijados en alabanza de san Vicente".

[19] “[p. 43] (...) lo primero que concerté fue que los cantores y menestriles avían de acudir todos juntos al officio y missa mayor, cantando la missa a dos coros, y con sus villancicos; y también avían de acudir todos ellos sin faltar alguno a las tardes, entreteniendo con música muy regozijada, concertando con ellos todo aquello que pidieron".

[20] 5-ago-1611, viernes, convento de Santo Domingo; exposición de la reliquia. "[p. 45] (...) y en la tarde huvo concurso de gente que llegaron a gozar de la [p. 46] música y adorar la santíssima reliquia".

[21] 6-ago-1611, sábado, convento de Santo Domingo; exposición de la reliquia. "[p. 46] Este día, además de la luminaria ordinaria y de muchos y differentes olores, a la tarde huvo música

\footnotetext{
12 Paginación indicada en el texto.
} 


\section{FranCESC ViLlanUeVa SERRANo}

de arpas y vigüelas y se cantaron unos sonetos y villancicos que fue muy apazible entretenimiento y de grandíssimo contento para todos los que assistieron".

[22] 7-ago-1611, domingo, convento de Santo Domingo; exposición de la reliquia. “[p. 48] (...) después de comer además de los menestriles y cantores conduzidos para todo el ochavario, quiso regozijar más la tarde el señor deán Frigola; truxo la capilla de la seo, que autorizó y regozijó por estremo con los motetes y villancicos que cantaron con aquella arte, melodía y suavidad que acostumbran. También acudieron algunos poetas con sus romances, sonetos y canciones dignas de sus ingenios, las quales leyeron con mucho gusto (...)".

[23] 8-ago-1611, lunes, convento de Santo Domingo; exposición de la reliquia. “[p. 49] (...) en la tarde, a la música y entretenimiento acudieron sus Señorías y otros [p. 50] cavalleros y damas y otra mucha gente, todos desseosos de adorar la santa reliquia, como realmente la adoraron".

[24] 9-ago-1611, martes, convento de Santo Domingo; exposición de la reliquia. "[p. 50] Y este día parece que se esmeraron más y aventajaron a sí mesmos los cantores y menestriles y se entretuvo con contento toda la tarde, y los olores fueron muy singulares. Y también se dio a adorar la santa reliquia, como todos los demás días se acostumbró, con mucho contento de la ciudad".

[25] 10-ago-1611, miércoles, convento de Santo Domingo; exposición de la reliquia. "[p. 51] Este día en la tarde cumplió la señora condesa de Carlet el desseo grande que tenía de regozijar estas fiestas y ochavario; y assí no se contentó con la fiesta que hizo el lunes sino que añadió para este día de san Lorenzo en la tarde una famosa máscara y dança; y dançaron en el [p. 52] coro delante la santa reliquia con mucho aplauso, regozijo y contento de todos los assistentes, que eran tantos que con mucho trabajo quedó lugar para los dançadores. Este mesmo día se juntaron muchos poetas de mucha habilidad e ingenio y leyeron muchos sonetos y romances (...)".

[26] 11-ago-1611, jueves, convento de Santo Domingo. "[p. 54] Y a la tarde, después de algún entretenimiento llegaron tres máscaras vestidas ricamente con sus achas blancas en las manos acompañadas con muchos menestriles y, llegado al coro, dançaron por su devoción por espacio de más de una hora, con tanta destreza, arte y ligereza que quedaron [p.55] todos admirados. Este mesmo día se cantaron completas con mucha solenidad y música assí de cantores como de menestriles y flautas" (Blasco, 1611'13).

El relato de Blasco muestra con claridad que el objeto de veneración ante el cual se realizaron estas sesiones vespertinas de música, poesía y danza no fue el Santísimo Sacramento sino las reliquias cuya llegada se festejaba, las cuales incluso se "daban a adorar" en algún momento de la tarde. En estas fiestas parece que predominaron las veladas musicales ya que en solo dos días consta que hubo lectura de poesía. Asimismo, la octava finalizó con dos sesiones de danza de máscaras, la primera de las cuales fue un obsequio especial de la condesa de Carlet, quien patrocinaba los actos de ese día de la octava. Del mismo modo, una demostración de liberalidad del deán de la seo Cristòfol Frigola hizo posible sumar la capilla catedralicia al grupo de cantores y ministriles, seguramente extravagantes o independientes, que habían sido contratados para todos los actos de la octava. Además de este género de músicos, que típicamente formaban parte de las plantillas

\footnotetext{
13 Paginación indicada en el texto.
} 
musicales estables de los templos, en este caso parece que solo en uno de los días intervinieron instrumentos de cuerda - arpas y vihuelas - con los que se cantaba música en romance. Como sucedió generalmente en celebraciones anteriores, al menos en la velada musical en que participaron los cantores de la catedral, también se cantaron piezas en latín como eran los motetes. Pedro Blasco informa también de cómo estas expresiones artísticas se disfrutaban con gran alegría por la numerosa concurrencia en un ambiente de agradables y variados olores.

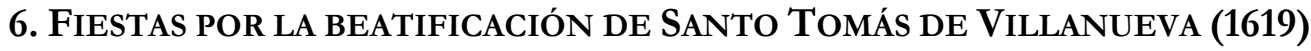

El 7 de octubre de 1618, el papa Pablo V ordenaba despachar el breve de beatificación de Tomás de Villanueva, fraile agustino toledano que había regido la archidiócesis valenciana desde 1544 hasta su muerte en 1555, aunque el documento no llegó a su sede catedralicia hasta finales de marzo del siguiente año. La capital del reino decidió festejar especialmente esta declaración que autorizaba el culto a un arzobispo que había dejado un espléndido recuerdo tras un siglo de pontífices absentistas. Fue precisamente un beneficiado de la catedral, Jerónimo Martínez de la Vega, quien se encargó en aquella ocasión de escribir la relación de estas fiestas que solo se extendieron durante tres días, además de la víspera del pregón y las dos veladas taurinas que tuvieron lugar unos días más tarde. Como era habitual, la primera jornada, domingo 28 de abril de 1619, acogió la misa solemne matutina mientras que el horario de tarde se cubrió con el oficio de vísperas y la procesión general que sirvió para trasladar la reliquia de la cabeza del beato desde el convento de Nuestra Señora del Socorro a la catedral, precediendo a las actividades nocturnas habituales de luminarias, fuegos artificiales y repique de campanas. Los dos días restantes hubo en la catedral misa solemne con sermón por la mañana y, tras los oficios de vísperas y completas, sesiones musicales cuyo desarrollo relata con extraordinario detalle Martínez de la Vega:

\section{8-abr-1619, domingo, procesión general.}

[27] 29-abr-1619, lunes, catedral; exposición de la cabeza del santo en el altar mayor. "[p. 337] Empleose la tarde de este día toda en música i poesía para que no faltara exercicio tan divino en fiesta tan solene i regozijada, repartiéndola en esto de manera que la poesía se leyese en el convento del Socorro en alabança de nuestro beato don Tomás, como en casa donde reposava su dichoso cuerpo, i la música en la Iglesia Mayor, porque así no faltara en ella cada día por mañana i tarde su particular festeo i regozijo. Acudió la gente a entrambas partes copiosísima siguiendo cada uno su particular inclinación i afecto, quién a la música i quién a la poesía".

[28] “[p. 385] Esta misma tarde (en el entretanto que se leyó la poesía en la iglesia del Socorro) en el aseo (dichas las vísperas i completas con la solenidad acostumbrada) estando la santa reliquia patente en medio el altar con mucho adorno, después de aver danzado ocho diestrísimos danzantes un torneo todos juntos i cada uno tras él diversas vezes danzas diferentes, se començó en la capilla mayor la música, con uno de los llenos i copiosos 


\section{FranCESC VillanUeVA SERRANO}

auditorios que se an visto a quien azía medio el ilustre cabildo i jurados que asistieron en la misma forma que a los divinos oficios.

Iziéronse (a esta causa) a los lados de la capilla dos como balcones o corredores curiosísimos que se arrojavan de la pared sus nueve palmos, arbitrio con que se dio mayor capacidad [p. 386] a la capilla i más ornato. Servía el de la mano izquierda para los ministriles i el de la drecha para cuatro músicos de guitarra, arpa i otros instrumentos con su bufete i su tapete cada uno en medio para los ministriles, baxones, cornetas, guitarras, arpas i papeles, todo lo cual estava fabricado de manera que no ocupava cosa alguna. En medio el pavimento de la capilla estava un facistol con ocho asientos para otros tantos músicos: ocho vigüelas de arco i un organillo de admirable echura, vozes i mixturas.

Por principio de la música i para combidar a silencio entraron los ministriles con un ecelentísimo motete, que dio singular satisfación a todos. Luego, los cuatro músicos con dos guitarras i un arpa cantaron el siguiente romance vertido:

$$
\text { Gozate Valencia noble, (...) }
$$

[p. 387] Prosiguió la capilla diziendo:

$$
\text { Y Valencia responde, áganse fuegos, (...) }
$$

[los cuatro músicos]

$$
\text { Tus ijos que desearon (...) }
$$

[la capilla]

$$
\text { Y Valencia, etc. (...) }
$$

[los cuatro músicos]

$$
\text { Levantar nuestra cabeza (...) }
$$

[la capilla]

$$
\text { [p. 388] Y Valencia responde, áganse fuegos, (...) }
$$

Acabada esta letra, cantaron los de las vigüelas de arco, con ellas, a ocho, este motete que pareció estremadamente de bien.

\section{Iam non dicam vos servos etc.}

Tocose el órgano un rato diestramente. Luego los músicos de guitarra con sola el arpa cantaron este villancico.

$$
\text { El que fue, en vida, socorro (...) }
$$

[p. 389] Acabava siempre el villancico toda la capilla i, en dexándose, luego los de las vigüelas de arco cantaron este motete ecelentísimo:

\section{Laudate Dominum, etc.}

En esto apareció otra copia aventurera de músicos de guitarra de divinas vozes que no causaron pequeño regozijo así por esto como por la novedad del caso. Cantaron luego, sosegado el auditorio, la siguiente letra:

\section{Martín de un pobre cubrió (...)}




\section{«CON LICENCIA DE LA DEVOCIÓN Y PRIVILEGIO DEL REGOZIJO»: LAS SIESTAS EN LAS CELEBRACIONES RELIGIOSAS EXTRAORDINARIAS DE LA VALENCIA SEISCENTISTA}

[p. 390] Luego la capilla toda, como en correspondencia del desafío, cantó con buena gracia i temple de los músicos, diziendo:

$$
\text { Llegó en la muerte Tomás (...) }
$$

Tañeron al punto el organillo un rato para dar lugar a templar de nuevo los instrumentos; i, puesto a punto, un tiple de la capilla cantó con el arpa solo este romance estremadamente de bien:

$$
\text { [p. 391] Aquel divino pastor, (...) }
$$

[p. 393] Pareció tan bien que se le mandaron cantar al otro día de mañana i tarde. Luego los cantores de guitarra i arpa cantaron con ellas esta letra:

$$
\text { Su descanso en la cama, (...) }
$$

[p. 395] Luego los minestriles, de que hay dos copias en esta santa Iglesia, tañeron acordadamente una resercada con los baxones y, tras ellos, la otra copia de guitarras aventureras salió cantando la presente letra:

$$
\text { Por tan santa cabeça, (...) }
$$

[p. 396] Cantáronse otros muchos villancicos admirables i dio fin a la música de esta tarde el segundo tiple de la capilla, que cantó en el arpa solo este romance, como en correspondencia del otro que cantó el primero:

$$
\text { Aquella blanca paloma (...) }
$$

[p. 399] Dexó suspenso el auditorio i quisieran emplear la noche toda, oyendo tan regaladas i divinas vozes, si no les estorbara el solenísimo repique de campanas i les llamara el nuevo regozijo de luzes, fuegos, incendios i otros entretenimientos (...)."

[29] 30-abr-1619, martes, catedral; exposición de la cabeza del santo en el altar mayor. "[p. 462] Este dia por la tarde se prosiguió, primero, la música que el día pasado i luego se acabó con el exercicio de la justa literaria, sentencia i destribución de premios del certamen, estando ya este día diputado para ello, como en su lugar se dixo.

Estuvo la capilla mayor con los cumplimientos, disposición i adorno referidos para la comodidad de sus músicos i sus instrumentos; i, previniendo al grande concurso de gente que en tal jornada podía presumirse (que fue en efeto grande, calificado i doto), se creció el rellano o pavimento de dicha capilla, levantando un tablado a su nivel con un bufete en medio [p. 463] cubierto de brocado i sus asientos para juezes, premios i papeles. Asistió todo el cabildo, jurados, nobleza, religiosos i clerecía de la seo, con lo restante del pueblo. La santa reliquia estuvo puesta en medio del altar con tanto adorno de luzes, relicarios i variedad de flores de mano i verdaderas, cual jamás se a visto.

Cantáronse las vísperas i completas en el coro con la solenidad i grandeza que los otros días; i, acabadas, se començó en la capilla mayor la música, con una entrada de ministriles preparando el auditorio; i luego los cuatro cantores de guitarras cantaron, con ellas, esta letra de Gerónymo Martínez de la Vega, presbýtero, cuyas son las demás que aquí refiero:

$$
\text { Ya a llamarse no se aplica (...) }
$$

[p. 464] Los baxoncillos después tañeron una resercada, que pareció admirablemente de bien; cantó tras ellos un tiple solo con el arpa este romance con no menos gusto del 


\section{FranCESC VillanUeVa SERRANo}

auditorio que las otras vezes, dando en nombre de Valencia el parabién a Villanueva, patria dichosa de nuestro beato.

$$
\text { Oye a Valencia la noble, (...) }
$$

[p. 466] Luego los músicos de guitarra aventureros (que también acudieron este día en competencia) cantaron con ellas i dos arpas esta letra:

$$
\text { Notable es Tomás, la fe (...) }
$$

El organillo, a ratos, entretenía el auditorio dando lugar a los músicos para prepararse, disimulándose así la no escusada detención de templar a cada paso. Luego, los cantores de guitarra cantaron la siguiente letra:

$$
\text { Tomás, pues guardáys ganado, (...) }
$$

[p. 467] Acabada esta letra, cantaron todos los de la capilla un ecelente motete i, tras él, los aventureros de guitarra en último lugar aqueste villancico si bien, a petición de muchos, se repitió primero algo de música del día antecedente:

$$
\text { Si aquel que no tiene es pobre, (...) }
$$

[p. 468] No se cansara el auditorio si todo el día se prosiguiera tan apazible entretenimiento pero, pidiendo lugar i tiempo la poesía, se dio con una resercada de ministriles fin a la música i principio a la justa, donde acudieron con gala $\mathrm{i}$ ardimiento mil bizarros i valientes justadores con orgulloso denuedo i porfía de sus devotísimas voluntades $i$ agudísimos ingenios. passando gallardamente su carrera. Fueron infinitos i acertados los papeles que este día se leyeron i muchos menos los premios que los justadores que les merecieron (...)" (Martínez de la Vega, 162014).

Insólitamente, el 29 de abril se celebraron sesiones de música y de poesía en templos diferentes y de modo simultáneo. La primera se reservó para la catedral, en cuyo altar mayor ya se encontraba patente la reliquia del nuevo beato y donde acudieron no solo los miembros del cabildo, sino también los jurados —máximos dirigentes de la ciudad-, mientras la segunda tuvo lugar en el convento del Socorro, donde descansaban los restos del antiguo arzobispo. La ubicación en la catedral y la asistencia de las más altas autoridades civiles parece translucir una mayor consideración o, al menos, aceptación de la música frente a la poesía por parte no solo del pueblo, que colmaba el templo, sino también de las clases dirigentes promotoras, quienes además dispusieron que aquella fuera precedida por una serie de danzas. El cronista nos brinda los pormenores de la ubicación en la capilla mayor de los también variados grupos musicales que tomaron parte en esta velada. La organización consideró que el acto, tanto de este día como del siguiente, merecía la instalación ex profeso de dos estructuras a modo de balcones en alto a ambos lados de la capilla, que acogieron a los ministriles - probablemente ocho (“dos copias") - y a un conjunto de cuatro músicos de cuerda pulsada, respectivamente. En el centro de la capilla se dispuso un numeroso grupo de vihuelas de arco - nuevamente ocho- y un órgano positivo, junto a los cuales, supuestamente, debieron de estar los cantores de la catedral que

\footnotetext{
${ }^{14}$ Paginación indicada en el texto.
} 
también participaron. Parece que la velada musical tuvo una larga duración, puesto que finalizó ya de noche. La inusual minuciosidad descriptiva de Martínez de la Vega permite comprobar la constante variedad, característica de la cultura barroca, presente en la sesión musical en diversos aspectos. Por un lado, los conjuntos nunca repetían en dos piezas consecutivas e incluso, en alguna ocasión se combinaban sus miembros, como sucedió con el romance con estribillo vertido a lo divino Gózate V alencia noble, en que los cantores de la capilla se hicieron cargo de los estribillos respondiendo a los cuatro músicos de guitarra y arpa que cantaron el resto del texto. Por otro lado, se interpretaron piezas en castellano -villancicos y romances-, otras en latín - motetes- y también música instrumental a cargo de intérpretes diversos. Las piezas en romance, predominantes en el acto, no solo se cantaron por los músicos de cuerda pulsada sino también por la capilla catedralicia o a solo por un tiple miembro de esta acompañado por un arpa. Curiosamente, mientras los cantores de la catedral se dedicaban a los regocijados villancicos y romances, los sobrios motetes fueron el único repertorio interpretado por los músicos contratados de vihuela de arco, que simultáneamente tañían y cantaban. Según las palabras del cronista, parece que la música instrumental tenía en gran medida funciones específicas de índole auxiliar en el acto: los ministriles se encargaron de la apertura "para combidar a silencio" a los asistentes mientras que el organillo se tañó "para dar lugar a templar de nuevo los instrumentos". Estos cometidos subalternos parecen ser un reflejo de la posición secundaria de la música instrumental respecto a la vocal propia del pensamiento de la época. El cronista precisa la interpretación por parte de los ministriles de un motete - un testimonio más de la práctica instrumental de música vocal en los templos- y de una recercada de bajones, un término que encabeza algunas piezas hispánicas de los siglos XVII a XIX conservadas en mayor proporción, precisamente, en Valencia. Se trata generalmente de obras a dos o tres voces para esta familia de instrumentos - aunque en las más recientes o copiadas tardíamente aparecen los oboes y fagotes-, que también incluyen acompañamiento ${ }^{15}$. Un curioso hecho acontecido en este acto, que sugiere la permisividad en su desarrollo de cierto espacio a la improvisación, fue la incorporación espontánea de un grupo de músicos de guitarra ("copia aventurera") que voluntariamente quisieron participar en el evento, los cuales fueron admitidos tras el revuelo que su irrupción ocasionó entre el auditorio. El día siguiente hubo además un certamen poético tras la velada musical, la cual siguió un patrón de características semejantes al del día anterior. Los conjuntos musicales participantes fueron los mismos que la jornada precedente -incluyendo a los músicos de guitarra "aventureros"- a excepción de los músicos de vihuela de arco, que estuvieron ausentes, posiblemente porque su lugar en la capilla había sido ocupado por un tablado con un bufete y los asientos para los jueces, premios y papeles de la justa poética que se debía celebrar posteriormente. En consecuencia, los motetes que cantaban y tañían estos músicos dejaron de escucharse, lo cual quizá fue el motivo por el que, en esta ocasión, fue la propia capilla catedralicia la que se encargó de cantar uno de ellos. En general, las piezas

15 Las piezas conservadas en Valencia están en E-VAcp y son de la autoría de Francisco Hernández (7), Francisco Vicente Cervera (3), Mariano Plasencia Valls (2), José Medina Garcerá (1) (Giménez Martínez, 2015: 366-368, 370, 387, 389-390). 


\section{FranCESC VillanUeVa SERRANo}

interpretadas para esta segunda velada musical fueron diferentes a excepción de algunas de la jornada anterior que se repitieron a petición del auditorio.

\section{Fiesta del convento de Nuestra Señora del Carmen a Santa Teresa de JESÚs (1621)}

El convento valenciano del Carmen organizó el 28 de octubre de 1621 una jornada festiva en honor de su, entonces aún beata, Teresa de Jesús. Según Mas i Usó, los carmelitas trataron así de demostrar su devoción tras una deslavazada participación valenciana en las fiestas de beatificación en 1614 (Mas i Usó, 1991: 237-238). El cronista del evento fray Manuel Mendoza, sacristán mayor del convento, relata que durante la tarde de esa jornada hubo en la iglesia un certamen poético:

[30] 28-oct-1621, convento del Carmen; certamen poético por la tarde. "En acabando de leer los poetas sus versos con grande aplauso y aprovación de todos, al son de los menestriles, que causaron grande alegría a los circunstantes, mandaron los juezes que se repartiessen los premios; y assí en una salvilla de plata se llevaron de uno en uno a cuyos eran, y todo con grande música y regozijo" (Mendoza, 1622: 188).

La música no estuvo ausente aunque, en esta ocasión —únicamente la instrumental— tuvo una función solemnizadora de ciertos momentos de un acto público —cometido muy habitual de los ministriles-, un contexto muy diferente al que se ha observado para las celebraciones anteriores, en que disfrutaba de una posición central. Como demuestra Ascensión Mazuela-Anguita, en certámenes poéticos celebrados en otros templos peninsulares fue común la integración de la música con cometidos similares al descrito por Mendoza; incluso en ocasiones esta se intercalaba con los poemas y con las sentencias de los jueces (Mazuela-Anguita, 2016: 42-43) ${ }^{16}$.

\section{Fiestas DE LA SEgUnda MitAd DE Siglo: INMACUlismo Y NUEVAS CANONIZACIONES}

Las relaciones de fiestas de la segunda mitad de siglo dejan constancia de la continuidad en la celebración de estas sesiones musicales desligadas de las ceremonias en gran parte de las celebraciones extraordinarias acontecidas en la ciudad aunque, ciertamente, las descripciones de estas son mucho más escuetas.

En pleno fervor inmaculista, los caballeros valencianos de la orden militar de Montesa decidieron realizar el 1 de junio de 1653 su particular voto a la Purísima Concepción de la Virgen María, que festejaron con un novenario en su iglesia del Temple sufragado particularmente por sus dirigentes. En la relación de estas fiestas, escrita por el

\footnotetext{
${ }^{16}$ Sobre los certámenes poéticos valencianos, véase Ferrando, 1983; Mas i Usó, 1991; Mas i Usó, 1996.
} 
caballero Lorenzo Matheu y Sans, consta la celebración de sesiones exclusivamente musicales durante todas las tardes de la novena:

[32] 1 a 9-jun-1653, Iglesia del Temple; imagen de la Virgen María en el altar. "[p. 55] Este día por la tarde huvo solenidad de música y se cantó por remate una Salve con mucha devoción. Y los ocho que hizimos las fiestas los siguientes días, como hermanos de la orden, anduvimos con toda conformidad; y assí cantó todos los días la missa la capilla de la Iglesia Mayor con toda la destreza que acostumbra y, por las tardes, divinos motetes y alabanças de nuestra gloriosa reina, rematando en una Salve o Letanía, conforme la elección de cada uno, que, acompañado de los olores, luzes y concurso del auditorio, tuvo todas las circunstancias que para mayor lucimiento se requerían".

[33] 9-jun-1653, Iglesia del Temple; imagen de la Virgen María en el altar. "[p. 61] (...) por la tarde, después de la música ordinaria, cantó la capilla una Letanía con muy grande dulçura y primor, concluyendo la fiesta con el mayor lucimiento, fervor y [p. 62] devoción que jamás se ha visto" (Matheu y Sans, 165317).

En este caso particular, la ausencia de una procesión general posibilitó que el mismo día del juramento tuviese lugar la primera velada musical. Aunque el cronista no aporta apenas detalles de su desarrollo, nos informa de la participación, una vez más, de la capilla catedralicia y del repertorio interpretado a base de motetes y "alabanzas", presumiblemente música en romance. Los mismos patrocinadores de cada jornada festiva elegían el texto de la pieza mariana en latín que cerraba cada sesión, entre la antífona Salve Regina o las Letanías a la Virgen. Asimismo, el autor resalta reiteradamente los efectos positivos que las veladas causaban entre el público por despertar su devoción, lo cual indica que Matheu y Sans compartía la opinión favorable a estos actos por esta razón, una posición que era frecuente pero no general. De hecho, en diversos lugares de la península -incluso en la casa profesa valenciana de la Compañía de Jesús- consta que se prohibieron con el argumento de la falta de decoro que provocaban entre los asistentes por tratarse fundamentalmente de un entretenimiento (Ezquerro Esteban, 2006: 1006; García Fraile, 2002: 383-384; Bombi, 2015: 170).

El 2 de julio de 1664, el papa Alejandro VII avanzó con un nuevo indulto, limitado a los reinos hispánicos y las Indias, en el reconocimiento a la Purísima Concepción de María que le concedía octava con precepto de rezo. Para festejarlo, se programaron una serie de actos variados a celebrar en diferentes jornadas y lugares de la ciudad. El primer día de fiestas, 4 de enero de 1665, fue patrocinado por el marqués de Astorga, virrey de Valencia, y consistió en una misa con sermón por la mañana y una cumplida sesión musical por la tarde:

\footnotetext{
17 Paginación indicada en el texto.
} 


\section{FranCESC VilLANUEVA SERRANo}

[34] 4-ene-1665, domingo, convento de San Francisco. "Diose fin a la missa, y prosiguiose la celebridad en la tarde con alegre armoniosa siesta, donde se imprimieron decentemente en el buen gusto, con licencia de la devoción y privilegio del regozijo varias letras que se cantaron; asistió también Su Excelencia y no poco ilustre séquito de nobles, con que coronado de estos luzidos festejos se retiró el día para dar lugar al siguiente del Certamen Poético. Escogiose entre las demás poesías que se cantaron en la siesta este romance:

$$
\text { En casa el mayor alférez (...)" (Torre y Sebil, 1665: 121) }
$$

El lunes 5-ene-1665, justa poética en el convento de San Francisco; el 1-feb, fiesta de lanzas; el 7 feb, sábado, comedia en el corral de la Olivera; el 12-abr, torneo en la plaza de Predicadores.

Por primera vez en las relaciones de fiestas valencianas, se constata aquí, en 1665, el uso del término siesta aplicado a este tipo de actos que, en adelante, se hallará sistemáticamente. No obstante, no puede decirse que con anterioridad el vocablo no estuviese en uso en la ciudad. De hecho, se dispone de testimonios de su empleo desde mediados de siglo en el contexto de las celebraciones del beato Luis Bertrán y el aniversario de su traslación en el convento de Santo Domingo, los cuales también prueban la organización de estos actos en fiestas ordinarias de ese centro religioso ${ }^{18}$. Pese a ello, parece que el uso de este término en Valencia no se inició hasta bien entrado el siglo XVII.

Por otra parte, en ocasión de la inauguración de la nueva capilla de la Virgen de los Desamparados, adscrita a la catedral aunque separada físicamente de esta, y la traslación de su imagen se celebró una octava de festejos a partir del 8 de mayo de 1667, siendo las tres primeras jornadas sufragadas por la ciudad y el resto por particulares. Solo consta que en los dos últimos días hubo siestas:

El 8-may-1667, día de la Virgen de los Desamparados, procesión general y traslado de la imagen a su nueva capilla.

[35] 14-may-1667, capilla de la Virgen de los Desamparados; imagen en el altar. “[p. 353] Prosiguió la tarde con solemne siesta (...).”

[36] 15-may-1667, día de la octava, capilla de la Virgen de los Desamparados; imagen en el altar. “[p. 503] (...) y con la misma celebridad de sonorosa música, devotos cánticos y general concurso remató la missa; prosiguiéndose la tarde con solemnes completas, alegre y festiva siesta donde, entre otras ingeniosas letras, se cantaron estos versos, proprios a la celebridad:

Los labradores que son (...)" (Torre y Sebil, 166819).

\footnotetext{
18 Los cronistas conventuales Jerónimo Pradas y Jaime Juan Falcó no usan el término siesta sino constantemente música para referirse a diversos de estos eventos celebrados desde 1602 a 1627 (E-VAu, Ms. 529, ff. 60r, 118v, 119r, 120r, 201r; E-VAu, Ms. 204, pp. 360, 384, 394, 412, 548). En cambio, su sucesor Domingo Alegre usa el vocablo siesta invariablemente desde su primer asiento referido a estos actos en 1648 (E-VAu, Ms. 157, ff. 162r, 180v, 201v, 208v, 224r, 262r, 272v, 276r, 281r, 301r). Las noticias musicales de las crónicas de Pradas y Alegre también pueden encontrarse en Bombi, 2017.

${ }^{19}$ Paginación indicada en el texto.
} 
Nuevamente, un convento festejaba una canonización —en este caso extraordinariade miembros de su propia orden. Los Trinitarios del convento del Remedio celebraron la canonización equivalente — reconocimiento por su veneración desde tiempos antiguos- de sus correligionarios San Juan de Mata y San Félix de Valois con una octava que comenzó el 28 de abril de 1668. Entre los actos programados también incluyeron una siesta el día de la octava tras las vísperas con la participación de la capilla de la catedral.

El 28-abr-1668, sábado, traslado de las imágenes de los santos a la catedral; el 29-abr, domingo, misa con sermón en la catedral y, por la tarde, procesión general; el 30-abr, lunes, misa y toros; el martes 1 may, misa y toros.

[37] 4-may-1668, viernes, convento del Remedio. “(...) la misma capilla empleó la tarde en vísperas y siesta, convirtiendo el coro y el templo en gloria (...)” (Rodríguez, 1669: 574).

Asimismo, la Compañía de Jesús homenajeó con fiestas a su nuevo santo Francisco de Borja, canonizado por Clemente X el 12 de abril de 1671. El jesuita Juan Bautista Bosquete reseñó concisamente tres días con siestas en la casa profesa con la participación, una vez más, de la capilla de la seo:

\section{El 1-oct-1671, jueves, fue la festividad del santo, con misa y procesión general.}

[38] 2-oct-1671, viernes, casa profesa de la Compañia de Jesús. "[p. 21] Cantó la capilla de la Iglesia Mayor. De tarde huvo siesta de las mejores vozes de la misma capilla; asistieron los Excelentísimos señores Virreyes (...)”.

[39] 4-oct-1671, domingo, casa profesa de la Compañia de Jesús. "[p. 22] Cantó la capilla de la Iglesia Mayor y de tarde huvo siesta de la misma capilla".

[40] 5-oct-1671, lunes, casa profesa de la Compañía de Jesús. “[p. 22] (...) y de tarde huvo siesta" (Bosquete, 167220).

Finalmente, la canonización del beato Luis Bertrán decretada por Clemente X el 12 de abril de 1671 motivó, además de los actos promovidos por la ciudad, la celebración de dos jornadas festivas particulares en el convento de Santo Domingo sufragadas por el colegio del Arte de la Notaría, al cual había pertenecido el padre del nuevo santo. El segundo de estos días, 8 de septiembre, hubo danzas antes del oficio de vísperas y posterior procesión particular.

El 7-sep-1671, procesión particular de traslado de la imagen del santo de la parroquia de San Esteban al convento de Santo Domingo y toros; el 8-sep por la mañana, misa solemne.

\footnotetext{
${ }^{20}$ Paginación indicada en el texto.
} 


\section{FranCESC VillanUeVa SERRANo}

[41] 8-sep-1671, convento de Santo Domingo. "[p. 308] Por la tarde dançaron en la iglesia las seis danças de toqueado, la de los enanos y la de palacio; y después la misma música [capilla de la catedral] cantó las vísperas; y acabadas salió la processión” (López de los Ríos, $\left.1674^{21}\right)$.

Estas danzas eran las mismas que el día anterior acompañaban la procesión distribuidas a lo largo de esta y que, tras el oficio vespertino, iba nuevamente a hacerlo esta jornada. El cronista destaca la "dança de Palacio" que iba acompañada de "arpa, vihuela, laúd y violón” (López de los Ríos, 1674: 245).

\section{CONCLUSIONES}

La literatura memorialística muestra diáfanamente que, durante las grandes celebraciones religiosas extraordinarias en la Valencia del Seiscientos, los templos —al menos la catedral y algunos conventos- fueron escenarios de actividades públicas vespertinas desvinculadas de las ceremonias. Estos actos podían incluir actuaciones musicales, lectura o certámenes de poesía y espectáculos de danza, que habitualmente se desarrollaban separadamente aunque ocasionalmente se combinaban. Tenían lugar antes o después de los oficios de vísperas y completas cumpliendo, al menos, la doble función de atraer público a estas funciones religiosas y completar el horario de tardes de las jornadas festivas posteriores al día primero y central de las celebraciones, en que solía haber procesión. Sus defensores también creían en su capacidad de mover a devoción a los asistentes aunque el ambiente excesivamente distendido en que tenían lugar motivó la existencia de detractores. Las sesiones exclusivamente musicales o siestas - término que en el caso valenciano se adoptó bien entrado el siglo- fueron un caso particular, aunque parece que también el más frecuente, de esta actividad extraceremonial desarrollada en los templos. En esta suerte de "conciertos espirituales", con frecuencia se congregaban capillas de cantores, ministriles, órganos positivos e, incluso, otros intérpretes no habituales en los iglesias como los conjuntos de vihuelas de arco y los músicos de guitarra, arpa, violín o rabel. En ocasiones, los cronistas precisan la ubicación de estos grupos en diversos espacios del templo, existentes o instalados a propósito, pese a que en ocasiones sus miembros actuaban conjuntamente, lo cual posiblemente obligaba a efectuar algunos desplazamientos. Los romances y villancicos relacionados con la festividad, interpretados por los cantores de las capillas o por los mismos músicos de cuerda, dominaban en estas veladas aunque también podía escucharse música en latín, como los motetes o los salmos que en ocasiones cerraban el acto musical. No parece que la música instrumental - a cargo de los ministriles y los órganos positivos, ocasionalmente con algún otro instrumento- fuese infrecuente en estas siestas aunque su función, según se señala en algún caso, era a menudo secundaria o auxiliar.

\footnotetext{
21 Paginación indicada en el texto.
} 
Así pues, la costumbre de celebrar siestas en festejos diferentes a los relacionados con el Santísimo Sacramento en la ciudad de Valencia no se inició en el siglo XVIII, como se suele admitir de modo general en la península, puesto que ya existía en el mismo inicio del siglo XVII. Ello ha quedado suficientemente probado, tanto para las celebraciones extraordinarias como, en el caso concreto del convento de Santo Domingo, también para las ordinarias. Además, su inclusión en los programas de festejos extraordinarios incluso se adelanta a las primeras noticias hasta el presente conocidas sobre inequívocas siestas en las festividades sacramentales no solo valencianas sino también hispánicas ${ }^{22}$. Es más, no se puede descartar que este tipo de actos se iniciaran con bastante anterioridad a los años finales del siglo XVI, cuando se suele considerar que se originaron en el ámbito peninsular. De hecho, la consueta de la catedral valenciana de 1527 ya incluye el aparente precedente de la sesión de "música de sonadors" que tenía lugar anualmente en la fiesta de Nuestra Señora de la Esperanza, tras el oficio de completas y la Salve ${ }^{23}$.

El conocimiento general actual sobre las siestas hispánicas se basa mayoritariamente en documentación catedralicia. En estas instituciones, la festividad del Corpus Christi era habitualmente la celebrada con mayor esplendor en el ciclo anual, a lo largo de una octava festiva, lo cual favorecía la celebración de estas sesiones musicales que permitían, sin demasiados dispendios, atraer al público a la iglesia al tiempo que completar el programa de actos sin recurrir a otros espectáculos de carácter más profano. Por ello, no es de extrañar que los ejemplos actualmente más conocidos en el ámbito catedralicio hispánico se refieran a esta festividad y que, por tanto, el Santísimo Sacramento aparezca siempre patente en el altar durante su desarrollo. No obstante, cuando se consulta otro tipo de documentación referida a celebraciones patrocinadas por otras instituciones o personas, como las que suelen tratarse en la literatura memorialística, se aprecia claramente, al menos en el ámbito valenciano, que las siestas no eran exclusivas de las fiestas sacramentales y que, en estos casos, los objetos de veneración presentes en el altar eran otros, como las reliquias o las imágenes.

El estudio de las relaciones de fiestas hispánicas desde el punto de vista de la historia de la música es todavía incipiente. A medida que se analice un mayor volumen de estos libros procedentes de otras ciudades peninsulares y se estudie también con profundidad la documentación conservada de otras instituciones promotoras de celebraciones religiosas - como los conventos, las parroquias o la cofradías - es probable que se pueda constatar que Valencia no fue un caso aislado.

\footnotetext{
22 Los documentos de época más antiguos hasta ahora publicados, según mi conocimiento, sobre inequívocas siestas en Valencia durante la octava de Corpus Christi son de 1655, procedentes de la catedral (Ramírez i Beneyto, 2006: 124); en el ámbito hispánico, es de 1602, relativo a la catedral de Palencia (citado en LópezCalo, 1983: 120-122).

23 "E aprés de les primeres vespres y completes, entre quatre y cinch, comencen a la Sperança unes completes, ab los chantres, y Salve; y aprés música de sonadors que dura fins a prop de les sis hores, la qual festa dexà mestre Martí Enyego, canonge de València” (E-VAc, no 70, f. 167v; edición en Serra Estellés, 2010: 312).
} 


\section{FranCESC VillanUEVA SERRANO}

\section{BIBLIOGRAFÍA}

Alenda y Mira, J. (1903). Relaciones de solemnidades y fiestas públicas de España, 2 vols. Madrid: Sucesores de Rivadeneyra.

Anónimo (1624). Fiestas que el convento de la Cartuxa de nuestra Señora de Portaceli de Valencia bizo en 24 de Setiembre 1623 al patriarcha S. Bruno. Y las que se bizieron en la Santa Metropolitana Iglesia de dicha Ciudad en 6 de Octubre del mesmo año; con el sermón que predicó el muy Rever. P. M. F. Miguel Guerau Doctor en Sancta Theología, Religioso del Real Convento de S. Miguel de los Reyes, Orden de San Gerónimo. Valencia: Felipe Mey.

Bejarano Pellicer, C. (2013). El mercado de la música en la Sevilla del Siglo de Oro. Sevilla: Universidad de Sevilla, Fundación Focus-Abengoa.

Blasco, P. (1611). Relación breve de la real merced que ba becho la Christianissima Reyna de Francia D. María, de la santa Reliquia o bueso de S. Vicente Ferrer, Valenciano, P. M. F. Juan Vicente Catalá, diffinidor por la provincia de Aragó, de la orden de Predicadores, en el capitulo general que se ha tenido en París, calificador del Santo Officio de la Inquisición, y prior d'este convento de Predicadores, con el recibimiento y fiestas que se le han hecho en esta su ciudad. Valencia: Junto al Molino de Rovella.

Bombi, A. (2007). "The third villancico was a motet': the villancico and related genres". En T. Knighton y A. Torrente (eds.), Devotional Music in the Iberian World, 1450-1800, pp. 149-187. Aldershot: Ashgate.

Bombi, A. (2008). "Pedagogy and politics: music and the arts in the Valencian academy (1690-1705)". Early Music, 36:4, pp. 557-573.

Bombi, A. (2012). Entre tradición y modernidad. El italianismo musical en Valencia (1685-1738), Serie Mayor, 4, 2 vols. Valencia: Institut Valencià de la Música.

Bombi, A. (2015). “Águilas canoras: Los jesuitas valencianos y la música”. Il Saggiatore musicale, 22:2, pp. 151-202.

Bombi, A. (2017). "Noticias musicales en las crónicas de Gerónimo Pradas y Domingo Alegre (siglo XVII)" [archivo PDF]. Recuperado de http://www.academia.edu/34391846/CRONISTAS.pdf (último acceso 1 de mayo de 2018). 
«CON LICENCIA DE LA DEVOCIÓN Y PRIVILEGIO DEL REGOZIJO»: LAS SIESTAS EN LAS CELEBRACIONES RELIGIOSAS EXTRAORDINARIAS DE LA VALENCIA SEISCENTISTA

Bosquete, J. B. (1672). Fiestas que bizo la casa professa de la Compañia de Iesús de Valencia a la canonización de San Francisco de Borja. Valencia: Gerónimo Vilagrasa.

Carreres Zacarés, S. (1925). Ensayo de una bibliografía de libros de fiestas celebradas en V alencia y su antiguo reino, 2 vols. Valencia: Imprenta Hijo de F. Vives Mora.

Ezquerro Esteban, A. (2002). "Siesta”, en E. Casares Rodicio (dir.). Diccionario de la Música Española e Hispanoamericana, vol. 9, pp. 1003-1007. Madrid: Sociedad General de Autores y Editores.

Ferrando i Francés, A. (1983). Els certàmens poètics valencians del segle XIV al XIX. Valencia: Institució Alfons el Magnànim, Institut de Literatura i Estudis Filològics.

Ferrer Ballester, Ma T. (2007). Antonio T. Ortells y su legado en la música barroca española, Serie Mayor, 2. Valencia: Institut Valencià de la Música.

Garbayo Montabes, F. J. (2013). "Estilo galante y sinfonías de F. J. Haydn en la capilla de música de la catedral de Santiago de Compostela durante el magisterio del Melchor López (1783-1822): La renovación del repertorio instrumental”. Anuario Musical, 68, pp. 263-292.

García Fraile, D. (2002). "Las siestas como actividad musical en las iglesias hispanas durante el Antiguo Régimen”. Nassarre, 18:1-2, pp. 375-436.

García Fraile, D. (2008). "Musical programming in Iberian and Latin American churches (1600-1800): musical 'siestas"'. En Organisateurs et formes d'organisation du concert en Europe 1700-1920: Institutionnalisation et pratiques. Musical life in Europe 1600-1900: Circulation, institutions, representation, 11, pp. 259-278. Berlín: BWV Berliner Wissenschafts-Verlag.

Giménez Martínez, O. (2015). Presencia y usos del bajón en Valencia durante los siglos XVI al XX $y$ transferencia de sus funciones al fagot. Tesis doctoral. Valencia: Universidad Politecnica de Valencia.

Gómez, V. (1602). Relación de las famosas fiestas que bizo la ciudad de Valencia a la canonización del bienaventurado S. Raymundo de Peñafort, en el Convento de Predicadores. Valencia: Juan Crisóstomo Garriz.

Gómez, V. (1609). Los sermones y fiestas que la ciudad de Valencia hizo por la Beatificación del glorioso padre san Luys Bertrán. Valencia: Juan Crisóstomo Garriz. 


\section{FranCESC ViLlanUeVa SERRANo}

Hathaway, J. (2007). “'Music charms the senses...': devotional music in the Triunfos festivos of San Ginés, Madrid, 1656". En T. Knighton y A. Torrente (eds.), Devotional Music in the Iberian World, 1450-1800, pp. 219-230. Aldershot: Ashgate.

Knighton, T. y A. Mazuela-Anguita (2015). "The soundscape of the ceremonies held for the beatification of St Teresa of Ávila in the Crown of Aragon, 1614”. Scripta, 6, pp. 225-250.

López-Calo, J. (1982). La música en la catedral de Palencia, vol. 3. Palencia: Diputación Provincial de Palencia.

López-Calo, J. (1983). Historia de la música española, 3. Siglo XVII. Madrid: Alianza Editorial. López-Calo, J. (2012). La música en las catedrales españolas. Colección Música Hispana, Textos, Estudios, 17. Madrid: ICCMU.

López de los Ríos, T. (1674). Auto glorioso. Festejo sagrado con que el insigne colegio de la preclara Arte de la Notaría celebró la Canonización del Señor San Luis Bertrán. Valencia: Gerónimo Vilagrasa.

Martínez de la Vega, J. (1620). Solenes i grandiosas fiestas que la noble i leal Ciudad de V alencia a echo por la Beatificación de su Santo Pastor i Padre D. Tomás de Villanueva. Valencia: Felipe Mey.

Mas i Usó, P. (1991). Justas, Academias y Convocatorias literarias en la Valencia Barroca (15911705). Teoría y práctica de una convención. Tesis doctoral. Valencia: Universitat de València.

Mas i Usó, P. (1996). Academias y justas literarias en la Valencia Barroca. Teoría y práctica de una convención. Kassel: Reichenberger.

Matheu y Sans, L. (1653). Relación en que la esclarecida religión y inclita Cavallería de Nuestra Señora de Montesa y San Iorge de Alfama, de la Milicia de Calatrava y Orden de Cístel da cuenta a la Católica Magestad del Rey nuestro señor, su administrador perpetuo, del voto y iuramento que hizo en Valencia a primero de Iunio mil seiscientos cincuenta y tres de defender, tener y sentir que la Virgen Santíssima María Madre de Dios fue concebida sin mancha ni rastro de pecado original, y fiestas que consagró a esta celebridad. Valencia: Bernardo Nogués.

Mazuela-Anguita, A. (2016). "La música en el certamen poético celebrado en Girona en diciembre de 1622". Quadrivium, 7, pp. 35-58. 
«CON LICENCIA DE LA DEVOCIÓN Y PRIVILEGIO DEL REGOZIJO»: LAS SIESTAS EN LAS CELEBRACIONES RELIGIOSAS EXTRAORDINARIAS DE LA VALENCIA SEISCENTISTA

Mendoza, M. (1622). Fiestas que el convento de nuestra Señora del Carmen de Valencia bizo a nuestra Santa Madre Teresa de Jesús, a 28 de octubre, 1621. Valencia: Felipe Mey.

Olson, G. (2005). "Imágenes sonoras en Valencia al final del Renacimiento”. En A. Bombi, J. J. Carreras, M. A. Marín (eds.), Música y cultura urbana en la edad moderna, pp. 279-294. Valencia: Universitat de València.

Ramírez i Beneyto, R. (2006). "Les migdiades musicals en València". Anuario Musical, 61, pp. 121-134.

Robledo Estaire, L. (1987). "Vihuelas y violones en la corte de Felipe III”, en J. LópezCalo, I. Fernández de la Cuesta, y E. Casares Rodicio (eds.). España en la música de Occidente: Actas del Congreso Internacional celebrado en Salamanca, 29 de octubre a 5 de noviembre de 1985, «Año europeo de la música», pp. 63-76. Madrid: Ministerio de Cultura, INAEM.

Robledo Estaire, L. (2006). "Música y cofradías madrileñas en el siglo XVII: Los Esclavos del Santísimo Sacramento de la Magdalena y los Esclavos del Santo Cristo de San Ginés”. Revista de Musicología, 29:2, pp. 481-520.

Robledo Estaire, L. (2013). "El patronazgo musical de la cofradía del "Ave María” y la consolidación de la ortodoxia católica en el Madrid del siglo XVII”. Resonancias, 33, pp. 103-126.

Rodríguez, J. (1669). Sacro y solemne novenario, públicas y luzidas fiestas que bizo el Real Convento de N. S. del Remedio de la Ciudad de Valencia a sus dos Gloriosos Patriarcas San Iuan de Matay San Félix de Valois, fundadores de la orden de la SS. Trinidad por la felize Declaración que de su antigua Santidad hizo Nuestro Santísimo Padre Alexandro VII. Valencia: Benito Macé.

Rodríguez, P. L. (1997/1998): “Música, devoción y esparcimiento en la capilla del Alcázar Real (siglo XVIII): Los villancicos y tonos al Santísimo Sacramento para Cuarenta Horas". Revista Portuguesa de Musicologia, 7-8, pp. 31-45.

Rodríguez, P. L. (2007). “The villancico as music of state in $17^{\text {th }}$-century Spain”. En T. Knighton y A. Torrente (eds.), Devotional Music in the Iberian World, 1450-1800, pp. 189-198. Aldershot: Ashgate.

Serra Estellés, X. (2010). La consueta de la seu de València dels segles XVI-XVII. Estudi i edició del ms. 405 de l'ACV. Vol 2.. Valencia: Facultad de Teología San Vicente Ferrer. 


\section{FranCESC VillanueVa SERRANO}

Tárrega, F. (1600). Relación de las fiestas que el arçobispo y cabildo de Valencia biżieron en la translación de la Reliquia del glorioso S. Vincente Ferrer a este santo Templo. Valencia: Pedro Patricio Mey.

Torre y Sebil, F. de la (1665). Luzees de la aurora, días del sol, en fiestas de la que es sol de los días, y aurora de las Luzes, María Santíssima. Motivadas por el nuevo indulto de Alexandro Séptimo, que concede octava con precepto de rezo de la Inmaculada Concepción. Valencia: Gerónimo Vilagrasa.

Torre y Sebil, F. de la (1668). Reales fiestas que dispuso la noble, insigne, coronada y siempre leal Ciudad de Valencia, a honor de la milagrosa Imagen de la Virgen de los Desamparados en la Translación a su nueva sumptuosa Capilla. Valencia: Gerónimo Vilagrasa.

Torrente, A. (2016). "VI. El villancico religioso". En A. Torrente (ed.), La música en el siglo XVII, Historia de la música en España e Hispanoamérica, vol. 3. Madrid: Fondo de Cultura Económica.

Fecha de recepción: 29/05/2018

Fecha de aceptación: 15/09/2018 